\title{
An Experimental Study of the Property of Phase Transition Temperature for Organic Composites Phase Change Materials
}

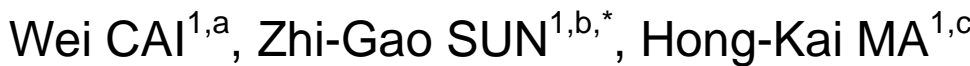 \\ ${ }^{1,2,3}$ School of Environmental Science and Engineering, Suzhou University of Science and \\ Technology , Suzhou 215009, China \\ accaiwei-1023@163.com, bszg.yzu@163.com, cmahongkai645@163.com \\ ${ }^{*}$ Corresponding author
}

Keywords: Fatty Acids, Fatty Alcohols, Composite Phase Change Material, Energy Storage.

\begin{abstract}
In order to obtain suitable phase change materials and phase transition temperature, a series of organic composite phase change materials were prepared with decanoic acid (CA), louric acid(LA), myristic acid (MA), palmitic acid (PA), stearic acid (SA) and 1-dodecanol (DE), tetradecanol (TD) as raw materials. The phase transition characteristics of the PCMs were measured through the method of cooling curves. Experimental results showed that organic composites phase change materials existed eutectic temperature. The eutectic temperature of the mixture of LA and SA was $30.6^{\circ} \mathrm{C}$. The eutectic temperature of the acid-acid-acid ternary system was slightly lower than that of the binary system. The eutectic temperature of the acid - alcohol binary system was the lowest among the three kinds of composites phase change materials, which was $23.1^{\circ} \mathrm{C}$. DE could reduce the crystallization temperature of $\mathrm{CA}$ as an additive.
\end{abstract}

\section{Introduction}

Phase change materials (PCMs) can store energy and regulate temperature through by the materials' endothermic and exothermic during their phase transition process. PCMs have been widely used in the fields of solar energy utilization, building energy efficiency, peak power shifting and waste heat recycling due to the advantages as phase change process with approximate constant temperature, large phase change latent heat, stable performance, etc[1-6]. The contradiction between supply and demand of energy (not match in time and space) can be solved by phase change energy storage. PCMs have been the research hotspot in recent years.

PCMs mainly include two categories, i.e. inorganic and organic. Supercooling, phase separation in the process of phase transition and the corrosion of construction materials restricted the use of inorganic phase change materials[1,2]. Among many PCMs, fatty acid has been widely used due to the advantages of large phase change latent heat, almost no supercooling and phase separation in the process of phase transition, small corrosive, etc. In actual projects, the phase transition temperature of the single fatty acids is often difficult to meet the needs of practical application. Single fatty alcohol is limited by its multiple freezing points caused by the morphology change in the process of solidification[4-8]. In this paper, several kinds of fatty acids and fatty alcohols were blended to form binary or ternary eutectic systems to seek appropriate phase change temperature. The phase change process and the stability of the eutectic system were also studied.

\section{Experimental}

\section{Materials and Equipments}

Capric acid (CA), Lauric acid (LA), Myristic acid (MA), Palmitic acid (PA), Stearic acid (SA) and 1-Dodecanol (DE), Tetradecanol (TD) were used as materials in the preparation of the composite PCMs, they were all AR, purchased from Tianjin Guangfu fine chemical institute without further purification.

Materials were weighed on an electronic balance (Sartorius BSA224S) with a readability of \pm 0.1 mg. A refrigerating bath, whose model was THD-2015 from Ningbo Tianheng Instrument Company, 
was used to control the experimental temperature. The refrigerating bath can maintain bath temperature within $\pm 0.05^{\circ} \mathrm{C}$ of the setpoint. Platinum resistance thermometers were used to measure the experimental temperature, with an accuracy of $\pm 0.1^{\circ} \mathrm{C}$. There was a data $\operatorname{logger}$ (Agilent 34970A) to record the temperatures in the experimental process as the function of time.

\section{Preparation of PCMs}

A certain amount of LA and MA weighed in advance were put into a beaker, after heating to $70^{\circ} \mathrm{C}$, stirring by the glass rod for 10min, the PCMs composed by LA and MA were completely prepared in the tubes. According to above method, a certain amount of composite phase change materials of LA-PA, LA-SA, LA-TD, CA-DE were prepared in the tubes .

The mass ratio of LA and PA were kept not changing, in which they formed eutectic system. A certain amount of MA were added into the composite materials of LA-PA, after heating to $70^{\circ} \mathrm{C}$, stirring by the glass rod for $10 \mathrm{~min}$, a certain amount of composite phase change materials of LA-PA-MA were prepared in the tubes .

\section{Experimental Process}

Cooling curve is often used during PCMs phase transition for thermal analysis. when the crystal precipitates from the liquid phase, the process of temperature exists a transition due to the release of latent heat. The phase change temperature can be found according to the position of the transition. As shown in Fig.1, composite phase change materials were put into the tubes which were immersed into constant temperature bath $\mathrm{A}$ (the temperature of bath A was about $70^{\circ} \mathrm{C}$ ). After the temperatures of PCMs were stable for 3 minutes in bath A, the PCMs were quickly taken out and put into the constant temperature bath $\mathrm{B}$ (the temperature of bath $\mathrm{B}$ was $0.2{ }^{\circ} \mathrm{C}$ ). During the cooling process, the temperatures were recorded by Agilent data logger. The time interval was $10 \mathrm{~s}$. The cooling curves of temperature and time were drawn. The T-x phase diagrams were also drawn.

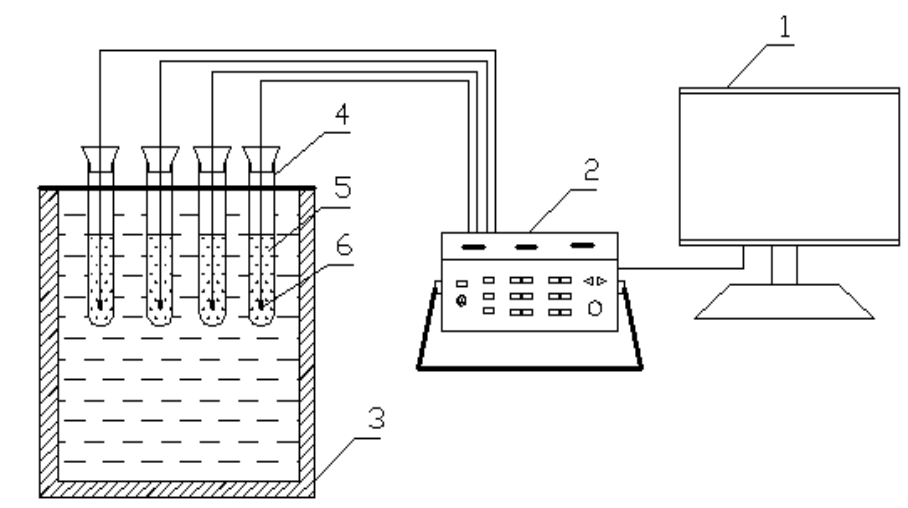

1-computer, 2-temperature datalogger, 3-constant temperature trough,

4-tube, 5-phase change materials, 6-Pt100

Fig.1 Experimental set-up

\section{Result and Discussion}

\section{Phase Transition Properties of Pure Substance}

The cooling curves of CA, LA, MA, PA, SA, DE and TD were shown in Fig. 2. It can be found that the seven organic materials all showed phase change in the process of solidification. All five fatty acids (CA, LA, MA, PA, SA) showed once crystallization, while the two fatty alcohols (DE and TD) both showed twice crystallization.

The phase change temperatures of pure organic materials were shown in Table 1. It presented that the supercooling degree existed in the solidification process of all the fatty acids, among which the supercooling degree of $\mathrm{CA}$ was the highest $\left(0.8{ }^{\circ} \mathrm{C}\right)$. The supercooling degree existed in the 
solidification process of DE $\left(1.4{ }^{\circ} \mathrm{C}\right)$, which was higher than that of all five fatty acids, while TD did not exist in the solidification process.

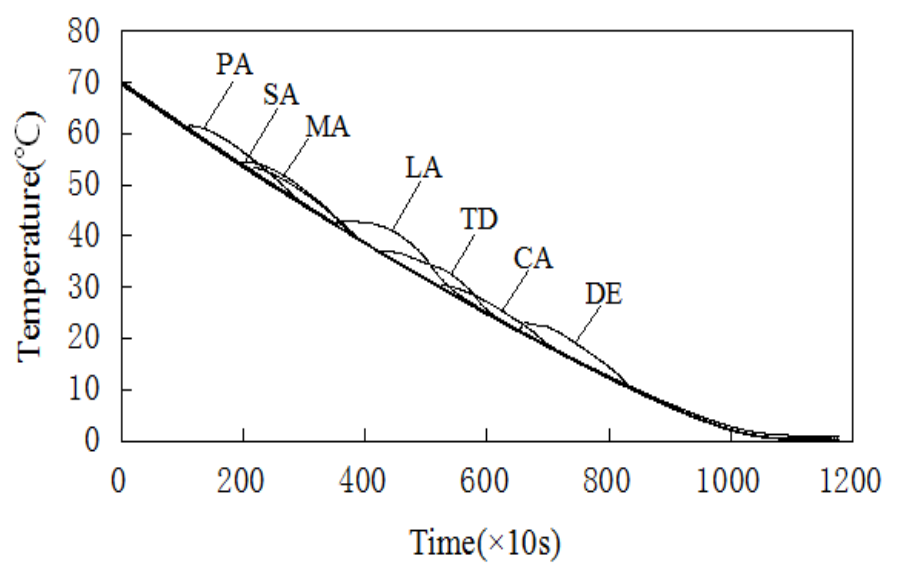

Fig.2 Cooling curves of organic phase change materials

Tab.1 Phase change temperature performance of organic materials

\begin{tabular}{cccc}
\hline PCMs & $\begin{array}{c}\text { Phase change } \\
\text { temperature/ } \\
{ }^{\circ} \mathrm{C}\end{array}$ & $\begin{array}{c}\text { Temperature of } \\
\text { secondary } \\
\text { crystallization } /{ }^{\circ} \mathrm{C}\end{array}$ & $\begin{array}{c}\text { Supercooling } \\
\text { degree } /{ }^{\circ} \mathrm{C}\end{array}$ \\
\hline CA & 30.1 & $/$ & 0.8 \\
LA & 42.6 & $/$ & 0.3 \\
MA & 52.7 & $/$ & 0.6 \\
PA & 61.1 & $/$ & 0.3 \\
SA & 54.3 & 22.5 & 0.1 \\
DE & 21.6 & 35.7 & 1.4 \\
TD & 37.1 & $/$ & 0 \\
\hline
\end{tabular}

\section{Phase Transition Properties of Binary Composite PCMs}

The T-x phase diagrams of the binary system were shown in Fig. 3 to 5. Fig. 3 showed that acid-acid binary system existed eutectic temperature. When the mass ratio of LA and MA was about $3: 1$, the LA-MA PCMs reached the eutectic temperature $\left(33.1^{\circ} \mathrm{C}\right)$. When the mass ratio of LA and PA was about $3: 1$, the LA-PA PCMs reached the eutectic temperature $\left(33.4^{\circ} \mathrm{C}\right)$. LA-SA PCMs reached the eutectic temperature $\left(30.6^{\circ} \mathrm{C}\right)$ at the mass ratio of $2: 1$. Fig. 4 presented that eutectic temperature also existed in the acid-alcohol binary system. When the mass ratio of LA and TD was about 3:4, the LA-TD PCMs reached the eutectic temperature $\left(23.1^{\circ} \mathrm{C}\right)$. Fig. 5 showed that the phase change temperature of CA was decreased by adding DE. When the mass fraction of DE added was $2.5 \%, 5 \%, 10 \%$, the phase change temperature of PCMs was reduced from $30.1{ }^{\circ} \mathrm{C}$ to $29.2{ }^{\circ} \mathrm{C}$, $28.3{ }^{\circ} \mathrm{C}$ and $25.6{ }^{\circ} \mathrm{C}$. It meant that $\mathrm{DE}$ could be used to regulate fatty acids phase transition temperature.

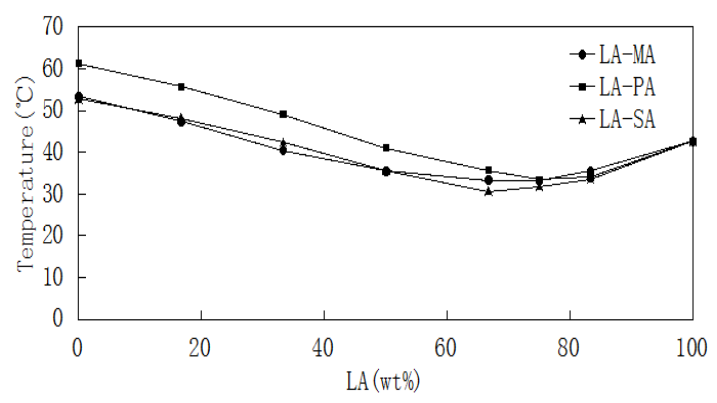

Fig.3 Binary system phase diagram of acid-acid 


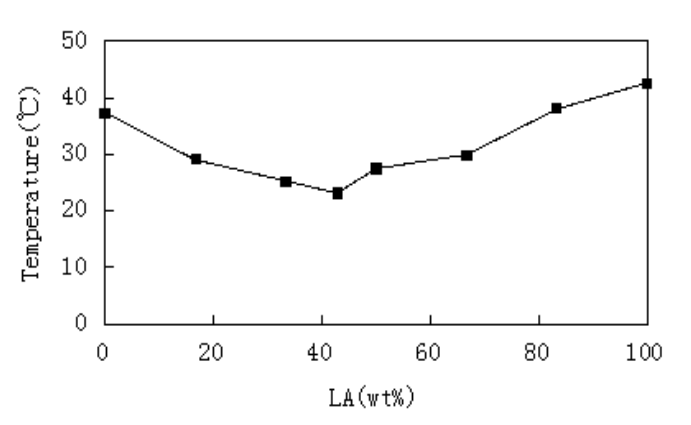

Fig.4 Binary system phase diagram of CA-DE

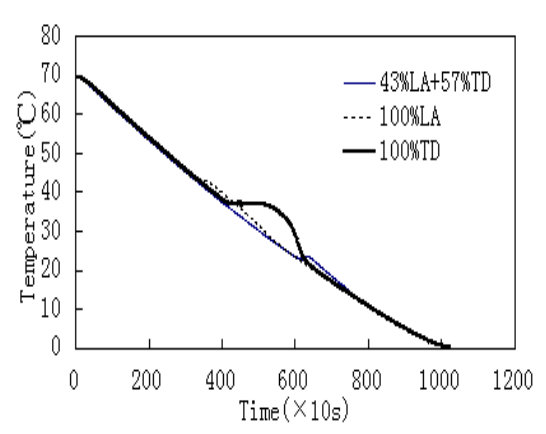

Fig.6 Cooling curves of LA-TD

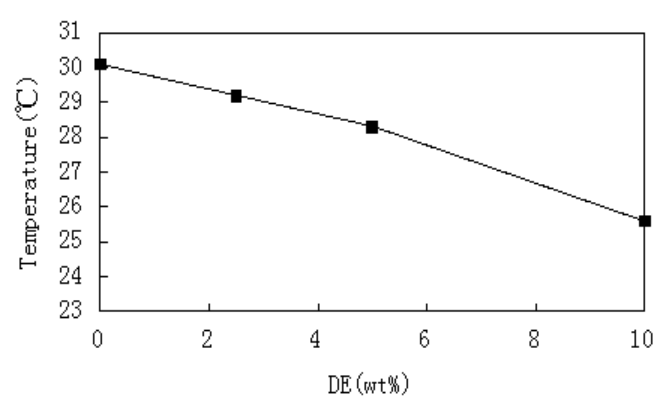

Fig.5 Binary system phase diagram of LA-TD

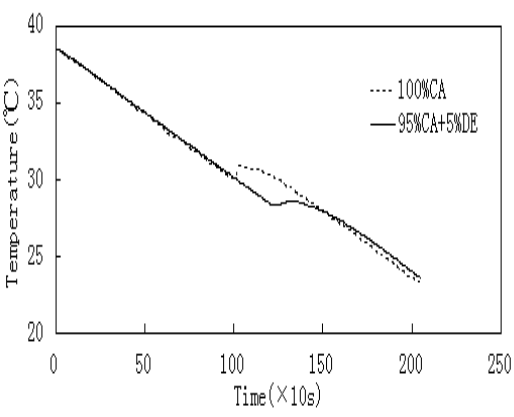

Fig.7 Cooling curves of CA-DE

The cooling curves of acid-alcohol binary systems were shown in Fig. 6 and 7. Fig. 6 showed that the supercooling degree of LA-TD was lower than LA and TD, but not great. It was the probability that the supercooling degree of pure fatty acid was minor. The crystallization occured only once in the cooling process of acid-alcohol composite materials, which meant that LA-TD PCM could not only get suitable phase change temperature, but also be used to solve the problem of multi-crystallization of single fatty alcohols during the cooling process. Fig. 7 showed that the supercooling degree of CA phase transition reduced to $0.6^{\circ} \mathrm{C}$ by adding addition DE.

\section{Phase Transition Properties of Ternary Composite PCMs}

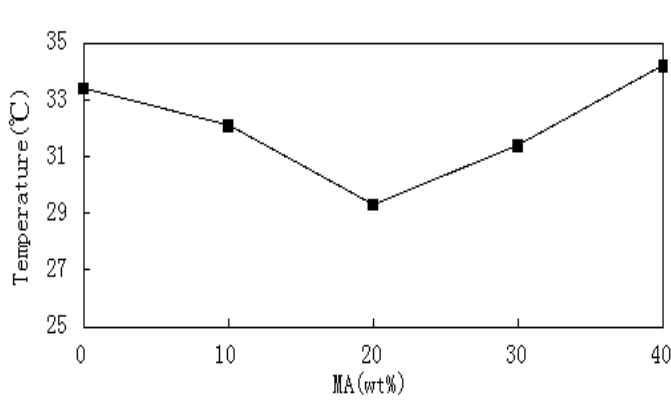

Fig. 8 Ternary system phase diagram of LA-PA-MA

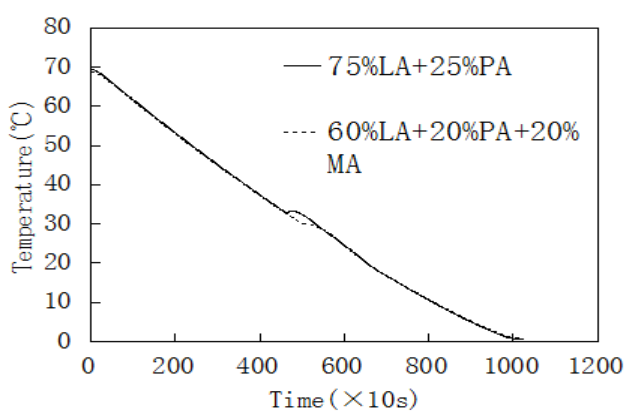

Fig. 9 Cooling curves of LA-PA and LA-PA-MA

T-x phase diagram of the ternary system of acid-acid-acid were shown in Fig. 8. Fig. 8 presented that there existed a eutectic temperature for the ternary system of acids. The ternary system reached the eutectic point $\left(29.3^{\circ} \mathrm{C}\right)$ when the mass fraction of LA, PA and MA were $60 \mathrm{wt} \%, 20 \mathrm{wt} \%$ and $20 \mathrm{wt} \%$. The eutectic temperature of ternary system was $4.1^{\circ} \mathrm{C}$ lower than that of binary systems, which meant the phase transition temperature of the ternary composite PCMs composed by LA, PA and MA was lower than that of the binary composite PCMs composed by LA and PA. The cooling 
curves of the ternary composed by LA, PA and MA in Fig. 9 showed that the supercooling degree of the ternary composite PCMs lowered slightly.

\section{Conclusions}

Binary and ternary composite PCMs composed by acid and alcohol were prepared. All the composites PCMs existed a eutectic temperature. The eutectic temperature of mixed materials of LA and MA, LA and PA, LA and PA were $33.1{ }^{\circ} \mathrm{C}, 33.4{ }^{\circ} \mathrm{C}$ and $30.6{ }^{\circ} \mathrm{C}$, respectively. The eutectic temperature of louric acid (LA) and tetradecanol (TD) was $23.1{ }^{\circ} \mathrm{C}$. The freezing point could be lowered to $28.3^{\circ} \mathrm{C}$ by adding DE (5 wt \%). The eutectic temperature of the ternary system composed by louric acid (LA), palmitic acid (PA) and myristic acid (MA) was $29.3{ }^{\circ} \mathrm{C}$, which was $13.3^{\circ} \mathrm{C}$ lower than louric acid (LA), and $4.1^{\circ} \mathrm{C}$ lower than the binary system composed by louric acid (LA) and palmitic acid (PA). The phase transition temperature of organic PCMs for thermal energy storage could be regulated to fit the needs.

The supercooling degree of organic materials was low, on which the binary or ternary composite systems of acids had little effect. The supercooling degree of the binary composite PCMs composed by $\mathrm{CA}$ and $\mathrm{DE}$ was $0.2^{\circ} \mathrm{C}$, which was lower than that of $\mathrm{CA}\left(0.8^{\circ} \mathrm{C}\right)$. The secondary crystallization of tetradecanol did not appear in the composite PCMs composed by LA and TD during the cooling process, which meant that the problem might been solved that multi-crystallization of single fatty alcohols always exits in the cooling process.

\section{Acknowledgement}

This work was financially supported by Natural Science of Foundation of Jiangsu Province (BK2012602), Suzhou Building and Construction Authority Project of Science and Technology of China (SJ201315) and Innovation Engineering of Graduate Student Training.

\section{References}

[1]X.F. He, Y. H. Wu, Y.M. Wang, L.N. Huang X.X. Cao, Research progress on phase change materials for thermal energy storage, New Chemical Materials. 42(2014)27-29.

[2]Sharmaa A, Tyagib V V, Chena C R, Buddhi D. Review on thermal energy storage with phase change materials and applications, J. Renewable and Sustainable Energy Reviews. 13(2009)318-345.

[3]M. Li, A nano-graphite/paraffin phase change material with high thermal conductivity, Applied Energy. 106(2013)25-30.

[4]H.G. Liu, H.B. Awbi, Performance f phase change material boards under natural convection, Building and Environment. 44(2009)1788-1793.

[5]Kenisarin M, Mahkamov K. Solar energy storage using phase change materials, J. Renewable and Sustainable Energy Reviews.11(2007)1913-1965.

[6]C. Martin, T. Bauer, H.M. Steinhagen, An experimental study of a non-eutectic mixture of KNO3 and NaNO3 with a melting range for thermal energy storage, Applied Thermal Engineering. 25(2013)159-166.

[7]L. Desgrosseilliers, C.A. Whitman, D. Groulx, M.A. White, Dodecanoic aid as a promising phase change material for thermal energy storage, Applied Thermal Engineering. 53(2013)37-41.

[8]J. Zuo, W. Li, L. Weng, Thermal performance of caprylic acid/1-dodecanol eutectic mixture as phase change material(PCM), J. Energy and Buildings. 3(2011)207-210. 